\title{
Determination of phenolic compounds of grape skins during ripening by NIR spectroscopy
}

\author{
Raúl Ferrer-Gallego, José Miguel Hernández-Hierro*, Julián C. Rivas-Gonzalo, M. Teresa Escribano-Bailón \\ Grupo de Investigación en Polifenoles. Unidad de Nutrición y Bromatología, Facultad de Farmacia, Universidad de Salamanca, Campus Miguel de Unamuno, \\ E 37007 Salamanca, Spain
}

\section{A R T I C L E I N F O}

\section{Article history:}

Received 7 July 2010

Received in revised form

24 November 2010

Accepted 2 December 2010

\section{Keywords:}

Polyphenols

Red grapes

Grape skins

Near infrared spectroscopy

Chemometrics

\begin{abstract}
A B S T R A C T
The potential of near infrared spectroscopy (NIRS) to determine the content of phenolic compounds in red grapes has been evaluated. The near infrared spectra of intact grapes and grape skins throughout maturity were recorded using a fibre-optic probe and a transport quartz cup, respectively. Reference values of phenolic compounds were obtained by HPLC-DAD-MS. Modified Partial Least Squares (MPLS) regression was used to develop the quantitative models for flavanols, flavonols, phenolic acids, anthocyanins and total phenolic compounds. The procedure reported here seems to have an excellent potential for fast and reasonable cost analysis. The results of this work show that the models developed using NIRS technology together with chemometric tools allow the quantification of total phenolic compounds and the families of main phenolic compounds in grape skins throughout maturation. The validation of these models showed the best results for the determination of flavonols (differences between HPLC and NIRS of $7.8 \%$ using grapes and $10.7 \%$ using grape skins) in the external validation procedure. Good results in the external validation were also obtained for the determination of total phenolic compounds (differences of $11.7 \%$ using grapes and $14.7 \%$ using grape skins). The best results were generally obtained recording the spectra directly in intact grapes.
\end{abstract}

(c) 2010 Elsevier Ltd. All rights reserved.

\section{Introduction}

The content of the different families of phenolic compounds and the total content of phenolic compounds in grapes provide noticeable information about the different ageing potential of wine (Moreno-Arribas \& Polo, 2008). The phenolic composition of grapes has also an important role in the definition of the organoleptic properties of wines. Anthocyanins are direct responsible of the color. Flavanols are particularly relevant for astringency (Kallithraka, Bakker, \& Clifford, 1998) and flavonols may have some influence on bitterness (Preys et al., 2006). Furthermore, flavanols, flavonols and phenolic acids provide support to wine color and ensure its stabilization during ageing as they can act as anthocyanin copigments. (Boulton, 2001; Gómez-Míguez, González-Manzano, Escribano-Bailón, Heredia, \& Santos-Buelga, 2006).

Global methods have been used to quantify polyphenols, such as the Glories method, PTI, Cromoenos ${ }^{\circledR}$ or the Folin-Ciocalteu index among others (Fragoso, Mestres, Busto, \& Guasch, 2010; Kontoudakis, Esteruelas, Fort, Canals, \& Zamora, 2009; OIV, 1990),

\footnotetext{
* Corresponding author. Tel.: +34 923294 537; fax: +34 923294515.

E-mail address: jmhhierro@usal.es (J.M. Hernández-Hierro).
}

but these methods are not able to distinguish between different families of phenolic compounds (i.e. flavanols, flavonols, etc.). To achieve this, the use of the high performance liquid chromatography (HPLC) coupled to diode array detection (DAD) and/or mass spectrometry (MS) is necessary (Cheynier \& Rigaud, 1986; Goldberg, Karumanchiri, Tsang, \& Soleas, 1998; Goldberg, Tsang, Karumanchiri, \& Soleas, 1998; Hong \& Wrolstad, 1990; Monagas, Suarez, Gomez-Cordoves, \& Bartolome, 2005; Wulf \& Nagel, 1978). However these techniques are time-consuming and expensive for monitoring changes in phenolic compounds throughout ripening.

Near infrared reflectance spectroscopy (NIRS) is a nondestructive technique, accurate, fast and that can be employed as a replacement for time-consuming chemical methods. NIRS has been proved to be a powerful analytical tool to determine phenolic compounds and other bioactive compounds in foodstuffs (McGoverin, Weeranantanaphan, Downey, \& Manley, 2010). Infrared spectroscopy has been used for the prediction of procyanidins in cocoa (Whitacre et al., 2003), for the determination of total polyphenol content in green tea using FT-NIR (Chen, Zhao, Liu, Cai, \& Liu, 2008), to evaluate phenolic changes occurring during development of olive fruit using ATR-FTIR (López-Sánchez, AyoraCañada, \& Molina-Díaz, 2009) and to determine malvidin-3- 
glucoside, tannins and pigmented polymers in wine (Cozzolino, Kwiatkowski et al., 2004; Jensen, Egebo, \& Meyer, 2008; Skogerson, Downey, Mazza, \& Boulton, 2007). This technology has also been used to measure, gluconic acid, glycerol, soluble solids and $\mathrm{pH}$ in grape juice (Versari, Parpinello, Mattioli, \& Galassi, 2008) and to determine condensed tannins, anthocyanins and the dry matter in homogenised red grape berries (Cozzolino, Cynkar, Dambergs, Mercurio, \& Smith, 2008; Janik, Cozzolino, Dambergs, Cynkar, \& Gishen, 2007). Moreover, some studies have also been performed directly in intact grape berries in order to determine total anthocyanins (Cozzolino, Dambergs, Janik, Cynkar, \& Gishen, 2006; Cozzolino, Esler et al., 2004), the concentration of extractable anthocyanins at $\mathrm{pH}$ equal to 1.0 and 3.2, the concentration of total polyphenols, the concentration of sugars and the density (Kemps, Leon, Best, De Baerdemaeker, \& De Ketelaere, 2010) using near infrared spectroscopy.

Due to the different roles that the main families of phenolic compounds could play in the chemical, functional and sensory properties of wine, their individual determination is of interest, especially using a single and rapid method of analysis. The aim of this study is to evaluate the potential of NIRS technology to determine the concentrations of the main phenolic families (flavanols, anthocyanins, flavonols and phenolic acids) and the total of phenolic compounds in grape skins and intact grapes. Furthermore, because of the advantages that fibre-optic probe attachment provides in comparison with the use of classic attachments: faster measures, easier clean up and simpler sample preparation; the use of this probe to record the spectra of intact grapes has also been evaluated. To our knowledge, this is the first time that NIRS has been used for simultaneously determining the main phenolic families and total phenolic compounds using a single spectroscopic method.
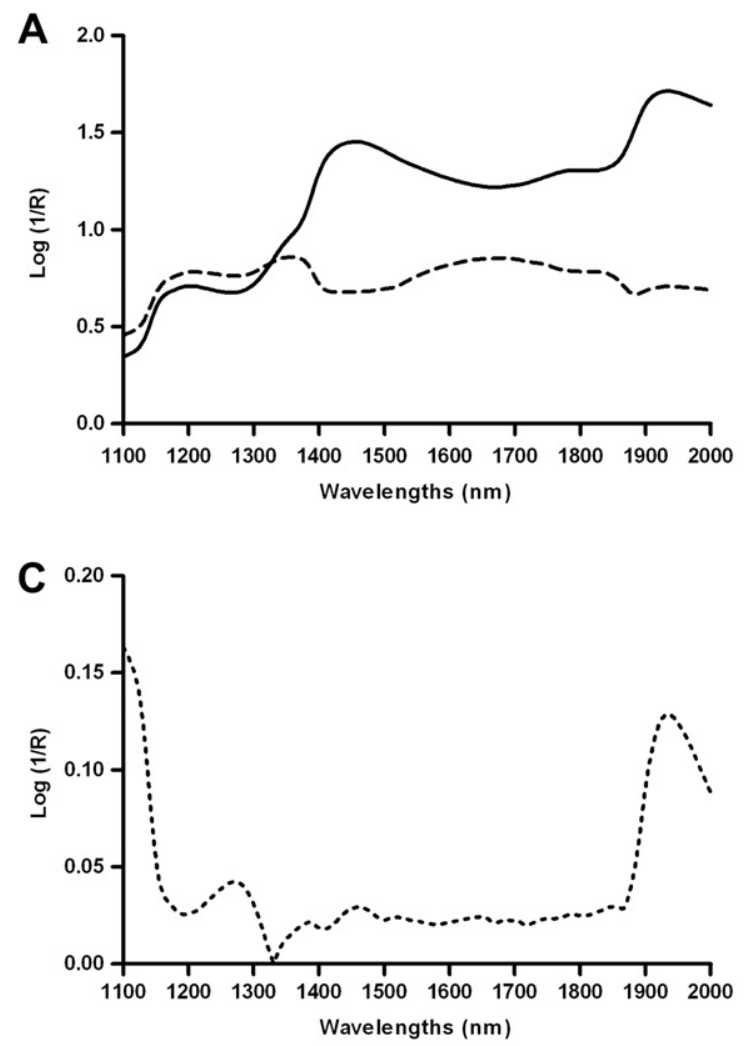

\section{Material and methods}

\subsection{Samples}

Vitis vinifera L. cv. "Graciano" red grape samples were collected from two different vineyards located in La Rioja (Spain). P.O.D La Rioja is divided into regions according to their agro-climatic characteristics. Vineyard 1 is located in Logroño (Rioja Media) and vineyard 2 is located $40 \mathrm{~km}$ away, in Haro (Rioja Alta). The first region is under the influence of Mediterranean climate while Rioja Alta generally is cooler and is under the influence of Atlantic climate.

In order to have a wide range of phenolic compounds concentrations to develop more suitable calibrations, the samples were collected at different developmental stages from veraison (September) to over-ripeness (November) in two different vintages (2008 and 2009). In the case of 2008 vintage seven dates were taken into account for vineyard 1 and eight for vineyard 2. For 2009 vintage the number of dates taken into account was six for vineyard 1 and seven for the vineyard 2. Three groups of 150 berries per vineyard were collected at each date. A total of 84 samples were collected in this study corresponding to 39 samples from vineyard 1 and 45 samples from vineyard 2 . The berries were collected from both sides of vines located in different rows within the vineyard. Edge rows and the first two vines in a row were avoided. Berries were collected from the top, middle and bottom of the cluster and were immediately frozen and stored at $-20^{\circ} \mathrm{C}$ until analyses were performed. Firstly, the samples were thawed and tempered at room temperature and the near infrared spectra of the intact grapes were recorded at room temperature which was controlled by an airconditioning device, grape skins were then separated manually
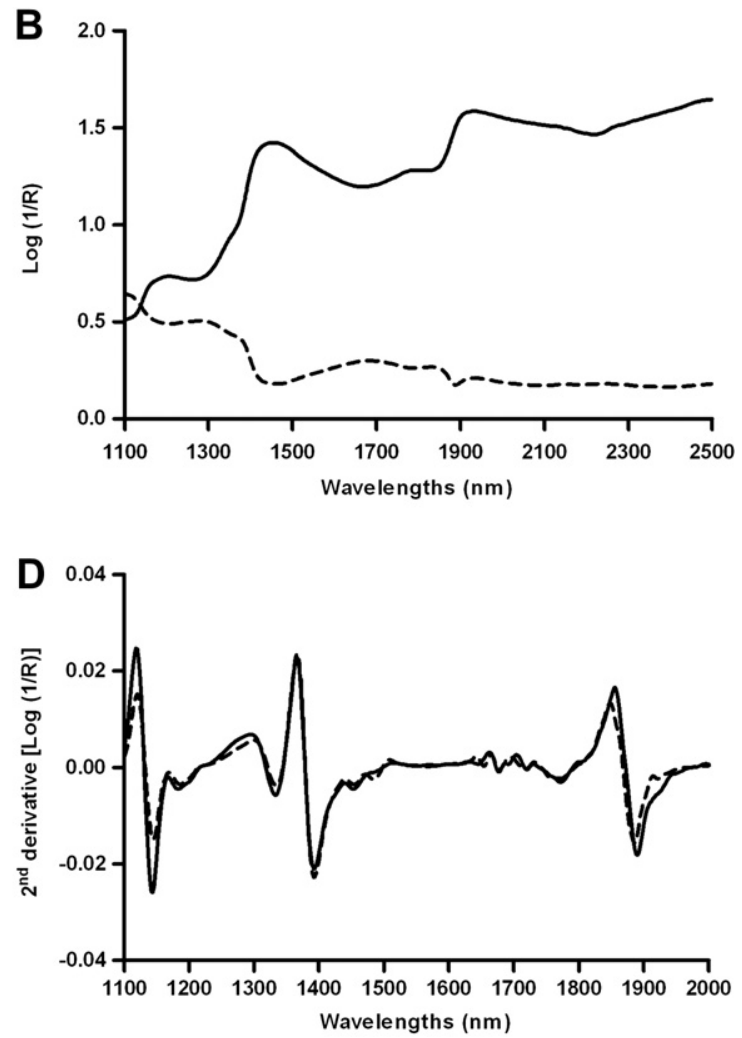

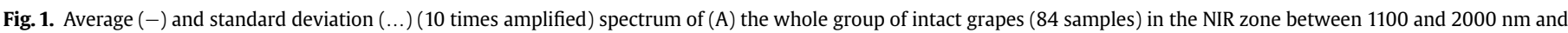

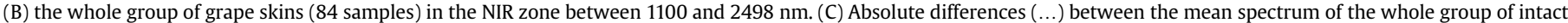

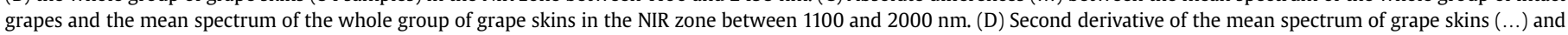
intact grapes (-) in the NIR zone between 1100 and $2000 \mathrm{~nm}$. 
from the whole grapes. Two subsamples were taken from each sample, one for the HPLC analysis and the other one for the near infrared analysis which was also carried out at room temperature.

\subsection{Phenolic extraction}

Ten grams of grape skins were macerated at $4{ }^{\circ} \mathrm{C}$ in methanol (Merck, LiChrosolv ${ }^{\circledR}$, Darmstadt, Germany) containing $0.1 \%$ of $12 \mathrm{M}$ $\mathrm{HCl}$. Methanolic phases were successively pooled, a few milliliters of water were added and the extract was concentrated under vacuum at $30{ }^{\circ} \mathrm{C}$ until methanol was removed and finally made up to $100 \mathrm{~mL}$ with ultrapure water. The aqueous extract was diluted $1: 2$ with $0.1 \mathrm{M} \mathrm{HCl}$, filtered through $0.45 \mu \mathrm{m}$ pore-size filters and directly injected into the chromatographic system to determine the flavonols and anthocyanins. In the case of flavanols and phenolic acids, an aliquot of the aqueous diluted extract was subjected to a clean up procedure using a cationic exchange cartridge (Oasis ${ }^{\circledR} \mathrm{MCX}$ ). The cartridge was previously conditioned with $2 \mathrm{~mL}$ of methanol and $2 \mathrm{~mL}$ of Milli-Q water and then the diluted extract $(2 \mathrm{~mL})$ was added to the cartridge. Sugars and other polar substances were removed by passing $4 \mathrm{~mL}$ of water. The flavanols and phenolic acids were eluted with methanol. The eluate was concentrated under vacuum and redissolved in $500 \mu \mathrm{L}$ of water. The eluate was injected into the chromatographic system after filtration through a $0.45 \mu \mathrm{m}$ pore-size filter. All analyses were performed in triplicate.

\subsection{HPLC analysis of phenolic compounds}

Chromatographic analyses were performed on a Hewlett-Packard 1200 Series HPLC equipped with an auto-injector, quaternary HPLC pump, column heater, diode array detection (DAD) and data treatment station. The HPLC-DAD-MS analyses were carried out in accordance with Ferrer-Gallego et al. (Ferrer-Gallego, GarcíaMarino, Hernández-Hierro, Rivas-Gonzalo, \& Escribano-Bailón, 2010) to determine flavanols and phenolic acids. Furthermore, the analyses of anthocyanins and flavonols were carried out in accordance with García-Marino et al. (García-Marino, Hernández-Hierro, Rivas-Gonzalo, \& Escribano-Bailón, 2010). Quantification was performed by HPLC-DAD using external calibration curves of purchased standards, unless standards of proanthocyanidins, which were obtained in our laboratory as described by GonzálezManzano et al., were employed (Gonzalez-Manzano, SantosBuelga, Perez-Alonso, Rivas-Gonzalo, \& Escribano-Bailon, 2006). The standard error was generally below $10 \%$ so the error and high degree of accuracy of the reference method was considered appropriate to use these data as reference values.

\subsection{Near infrared spectroscopy analysis and chemometrics}

The eighty four subsamples of grape skins and intact grapes were used to carry out near infrared spectroscopy analysis. A Foss NIRS system 5000 was used. The spectra were recorded at intervals of $2 \mathrm{~nm}$, performing 32 scans for both reference and samples. The fibre-optic probe employs a remote reflectance system and a ceramic plate as reference. The window is of quartz with a $5 \times 5$ $\mathrm{cm}$ surface area, measuring reflectance in the NIR zone over a wavelength range of $1100-2000 \mathrm{~nm}$. The NIR spectra were recorded by direct application of the fibre-optic probe onto the intact grapes. The whole data set was constituted by 84 intact grape samples and 451 data points per sample. Fig. 1 shows the average and standard deviation spectrum of the whole group (84 intact grape samples) in the NIR zone between 1100 and $2000 \mathrm{~nm}$.

The transport quartz cup with a window surface of $4.7 \mathrm{~cm} \times 5.7 \mathrm{~cm}$ and an optical pathway of $1.7 \mathrm{~cm}$ was used in the $1 /$ 2 full mode (i.e. grape skins covering $1 / 2$ of the surface windows) to record the reflectance spectra of grape skins. In this case, the measurements were made in the NIR zone over a wavelength range of $1100-2498 \mathrm{~nm}$. The whole data set was constituted by 84 grape skin samples and 700 data points per sample. Fig. 1 shows the average and standard deviation spectrum of the whole group (84 grape skin samples) in the NIR zone between 1100 and $2498 \mathrm{~nm}$.

The software used was Win ISI ${ }^{\circledR}$ (v1.50) (Infrasoft International, LLC, Port. Matilda, PA, USA). This software allows not only the spectral acquisition but also the data treatment and the development of the quantitative models. From the three samples of each date, one (33\%) was randomly allocated to the validation set and the other two (66\%) to the calibration set. Consequently, from the 84 samples of each sample presentation, i.e. intact grapes and grape skins, 56 samples were allocated in the calibration set and the remaining 28 samples were allocated in the validation set.

Prior to the quantitative analysis, principal component analysis (PCA), an unsupervised pattern recognition technique, was used in order to provide information about the latent structure of the spectral data and to identify spectral outliers according to their Mahalanobis distance (H-outliers). These outliers were eliminated at this stage.

The spectral data were pre-treated with Multiplicative Scatter Correction (MSC), Standard Normal Variate (SNV) and Detrend to remove the effects of scattering (Dhanoa, Lister, \& Barnes, 1995; Geladi, MacDougall, \& Martens, 1985). Moreover, several mathematical treatments were tested in the development of the NIRS calibrations, a, b, c, d, where the first digit is the number of the derivative; the second is the gap over which the derivative is calculated; the third is the number of data points in a running average or smoothing, and the fourth is the second smoothing (Shenk \& Westerhaus, 1995). The calibrations were performed by modified partial least squares regression (MPLS), which is often more stable and accurate than the standard PLS algorithm. In MPLS the NIRS residuals at each wavelength obtained after each factor has been calculated were standardised (dividing by the standard deviations of the residuals at each wavelength) before calculating the next factor (Shenk \& Westerhaus, 1995). For cross-validation, the calibration set was divided into several groups ( 6 groups in this case); each group was then validated using a calibration developed with the other samples. In this process another type of outliers ( $\mathrm{T}$ outliers) was identified which presents high residuals when predicted by the model generated in the cross-validation process. The final calibration models were developed after eliminating these outliers. Finally, validation errors were combined into a standard error of cross-validation (SECV).

\section{Results and discussion}

\subsection{Chemical analysis}

Up to 41 phenolic compounds were determined by HPLC-DADMS. The phenolic compounds were grouped taking into account their basic structures. The range, mean value and the standard deviation of the concentrations of flavanols, flavonols, anthocyanins and phenolic acids are shown in Table 1.

Table 1

Phenolic compounds content in $\mathrm{mg} \mathrm{g}^{-1}$ of grape skins.

\begin{tabular}{lllll}
\hline & Minimum & Maximum & Mean & SD $^{\mathrm{a}}$ \\
\hline Anthocyanins & 0.24 & 11.14 & 4.41 & 2.56 \\
Flavonols & 0.54 & 1.75 & 1.24 & 0.34 \\
Flavanols & 0.41 & 6.92 & 3.14 & 2.08 \\
Phenolic acids & 0.10 & 0.76 & 0.43 & 0.17 \\
Total & 1.95 & 18.35 & 9.23 & 4.61 \\
\hline
\end{tabular}

${ }^{\mathrm{a}} \mathrm{SD}=$ Standard Deviation $(n=84)$. 
Table 2

Calibration statistical descriptors ${ }^{\mathrm{a}}$ for the NIRS models in intact grapes ( $\mathrm{mg} \mathrm{g}^{-1}$ of grape skins).

\begin{tabular}{|c|c|c|c|c|c|c|c|c|c|c|c|c|}
\hline $\begin{array}{l}\text { Spectral } \\
\text { pre-treatments }\end{array}$ & $\begin{array}{l}\text { Phenolic } \\
\text { compounds }\end{array}$ & $\begin{array}{l}\mathrm{T} \\
\text { outliers }\end{array}$ & $\mathrm{N}$ & $\begin{array}{l}\text { PLS } \\
\text { factors }\end{array}$ & $\begin{array}{l}\text { Mean } \\
\left(\mathrm{mg} \mathrm{g}^{-1}\right)\end{array}$ & $\begin{array}{l}\mathrm{SD} \\
\left(\mathrm{mg} \mathrm{g}^{-1}\right)\end{array}$ & $\begin{array}{l}\text { Minimum } \\
\left(\mathrm{mg} \mathrm{g}^{-1}\right)\end{array}$ & $\begin{array}{l}\text { Maximum } \\
\left(\mathrm{mg} \mathrm{g}^{-1}\right)\end{array}$ & $\begin{array}{l}\text { SEC } \\
\left(\mathrm{mg} \mathrm{g}^{-1}\right)\end{array}$ & RSQ & $\begin{array}{l}\text { SECV } \\
\left(\mathrm{mg} \mathrm{g}^{-1}\right)\end{array}$ & $\mathrm{VC}^{\mathrm{b}}(\%)$ \\
\hline Std. MSC $2,4,4,1$ & Anthocyanins & 0 & 56 & 6 & 4.41 & 2.56 & 0.00 & 12.10 & 0.56 & 0.952 & 1.10 & 12.76 \\
\hline SNV 2,8,6,1 & Phenolic acids & 2 & 54 & 5 & 0.42 & 0.17 & 0.00 & 0.93 & 0.08 & 0.747 & 0.11 & 20.25 \\
\hline SNV 2,8,6,1 & Flavanols & 4 & 52 & 7 & 3.11 & 2.04 & 0.00 & 9.23 & 0.38 & 0.966 & 0.59 & 12.08 \\
\hline None $2,4,4,1$ & Flavonols & 0 & 56 & 6 & 1.24 & 0.34 & 0.23 & 2.26 & 0.09 & 0.933 & 0.16 & 7.01 \\
\hline SNV $2,4,4,1$ & Total & 2 & 54 & 6 & 9.17 & 4.69 & 0.00 & 23.23 & 0.63 & 0.982 & 1.33 & 6.87 \\
\hline
\end{tabular}

${ }^{\text {a }} \mathrm{N}$ : number of samples; SD: standard deviation; SEC: standard error of calibration; RSQ: coefficient of determination; SECV: standard error of cross-validation.

b $\mathrm{VC}(\%)=(\mathrm{SEC} / \mathrm{Mean}) \cdot 100$.

Table 3

Calibration statistical descriptors ${ }^{\mathrm{a}}$ for the NIRS models in grape skins ( $\mathrm{mg} \mathrm{g}^{-1}$ of grape skins).

\begin{tabular}{|c|c|c|c|c|c|c|c|c|c|c|c|c|}
\hline $\begin{array}{l}\text { Spectral } \\
\text { pre-treatments }\end{array}$ & $\begin{array}{l}\text { Phenolic } \\
\text { compounds }\end{array}$ & $\begin{array}{l}\mathrm{T} \\
\text { outliers }\end{array}$ & $\mathrm{N}$ & $\begin{array}{l}\text { PLS } \\
\text { factors }\end{array}$ & $\begin{array}{l}\text { Mean } \\
\left(\mathrm{mg} \mathrm{g}^{-1}\right)\end{array}$ & $\begin{array}{l}\mathrm{SD} \\
\left(\mathrm{mg} \mathrm{g}^{-1}\right)\end{array}$ & $\begin{array}{l}\text { Minimum } \\
\left(\mathrm{mg} \mathrm{g}^{-1}\right)\end{array}$ & $\begin{array}{l}\text { Maximum } \\
\left(\mathrm{mg} \mathrm{g}^{-1}\right)\end{array}$ & $\begin{array}{l}\text { SEC } \\
\left(\mathrm{mg} \mathrm{g}^{-1}\right)\end{array}$ & RSQ & $\begin{array}{l}\text { SECV } \\
\left(\mathrm{mg} \mathrm{g}^{-1}\right)\end{array}$ & $\mathrm{VC}^{\mathrm{b}}(\%)$ \\
\hline None $1,4,4,1$ & Anthocyanins & 2 & 54 & 7 & 4.17 & 2.24 & 0.00 & 10.90 & 0.39 & 0.970 & 0.66 & 9.33 \\
\hline Detrend 2,4,4,1 & Phenolic acids & 1 & 55 & 6 & 0.42 & 0.16 & 0.00 & 0.91 & 0.04 & 0.941 & 0.12 & 9.55 \\
\hline Std. MSC $2,4,4,1$ & Flavanols & 2 & 54 & 7 & 3.14 & 2.12 & 0.00 & 9.50 & 0.17 & 0.994 & 0.68 & 5.38 \\
\hline SNV 2,4,4,1 & Flavonols & 3 & 53 & 7 & 1.28 & 0.31 & 0.36 & 2.20 & 0.03 & 0.993 & 0.11 & 2.07 \\
\hline SNV $2,4,4,1$ & Total & 0 & 56 & 5 & 9.23 & 4.61 & 0.00 & 23.06 & 0.65 & 0.980 & 1.34 & 7.07 \\
\hline
\end{tabular}

${ }^{\text {a }} \mathrm{N}$ : number of samples; SD: standard deviation; SEC: standard error of calibration; RSQ: coefficient of determination; SECV: standard error of cross-validation.

b $\mathrm{VC}(\%)=(\mathrm{SEC} / \mathrm{Mean}) \cdot 100$.

\subsection{NIRS analysis}

A spectral pre-treatment (SNV 2,4,4,1) was applied to NIR raw data of samples from the calibration set and then PCA was carried out. This method provides not only information related to the spectral outliers and distribution of the samples in the created space, but it is also an important source of knowledge for the creation of cross-validation groups used in the calibration process. The cross-validation groups were created according to the $\mathrm{H}$ distance thus the groups presented a homogeneous distribution of samples among groups but heterogeneous within groups according to their $\mathrm{H}$ distance. Moreover, this is a useful tool to identify whether unknown samples do not belong to the spectral space $(H>3)$ created by the samples from which the models were developed (Brereton, 2003; Shenk \& Westerhaus, 1995). The spectral variability explained in grapes was $97.9 \%$ and 9 principal components were required. For the grape skins the spectral variability explained was $97.1 \%$ and 14 principal components were required. It is noticeable that in the case of grape skins more principal components were required to explain similar spectral variability. This could be due to the fact that the spectral data matrix of grape skins presented a more complex structure and the manipulation of the sample often introduces a major source of variation. Thus, the use of intact grapes avoids interferences that may be due to the manipulation of the sample. The spectra of the samples were ranked in order of their $\mathrm{H}$ (Mahalanobis) distance from the mean spectrum of all the spectra and the $H>3$ criterion was applied. H-outliers were not found either in grapes or grape skins.

The calibrations were performed by modified partial least squares regression (MPLS) testing different spectral pre-treatments. The optimum number of PLS terms used for the calibration was determined by cross-validation taking into account 6 groups. Tables 2 and 3 show the statistical parameters of the final calibration equations for the grapes and the grape skins, respectively. These tables show the number of samples used to obtain the calibration equation $(N)$ after eliminating outliers based on the $T$ value $(T>2.5)$. The best of the different mathematical treatments, concentration range and standard deviation are also shown. The performance of the calibration is expressed as the standard error of cross-validation (SECV).

The spectral regions close to 1140 and $1320 \mathrm{~nm}$ presented important contributions to the loadings of the models and are mainly related to combination bands of the $-\mathrm{OH}$ functional group, symmetric and anti-symmetric stretching. This wavelength region is also related to $\mathrm{C}-\mathrm{H}$ aromatic second overtones and $\mathrm{C}-\mathrm{H}$ third overtones (Osborne, Fearn, \& Hindle, 1993; Siesler, Ozaky, Kawata, \& Heise, 2002). These can be attributed to the chemical structure of the compounds analysed. Fig. 1 shows the standard deviation spectrum of the whole group and the highest deviation was around 1100-1300 nm which was also the most important zone used in the development of the PLS models in both cases (i.e. intact grapes and grape skins). Moreover, differences in the spectra and the second derivative spectra were observed around the $\mathrm{O}-\mathrm{H}$ bands regarding

Table 4

Internal and external validation of quantitative NIRS models in intact grapes ( $\mathrm{mg} \mathrm{g}^{-1}$ of grape skins).

\begin{tabular}{|c|c|c|c|c|c|c|c|}
\hline \multirow[t]{2}{*}{ Phenolic compounds } & \multicolumn{5}{|c|}{ Internal validation ( $\mathrm{N}^{\mathrm{a}}$ samples) } & \multicolumn{2}{|c|}{ External validation (28 samples) } \\
\hline & $\mathrm{N}^{\mathrm{a}}$ & $\mathrm{RPD}^{\mathrm{b}}$ & $\mathrm{RSQ}^{\mathrm{c}}$ & $\operatorname{SEP}^{\mathrm{C}}\left(\mathrm{mg} \mathrm{g}^{-1}\right)$ & $\operatorname{SEP}(C)^{\mathrm{C}}\left(\mathrm{mg} \mathrm{g}^{-1}\right)$ & Differences (\%) & $\overline{\operatorname{SEP}^{c}\left(\mathrm{mg} \mathrm{g}^{-1}\right)}$ \\
\hline Anthocyanins & 56 & 4.8 & 0.957 & 0.53 & 0.53 & 43.9 & 1.09 \\
\hline Phenolic acids & 54 & 2.1 & 0.766 & 0.08 & 0.08 & 27.3 & 0.13 \\
\hline Flavanols & 52 & 5.8 & 0.971 & 0.35 & 0.35 & 27.8 & 0.72 \\
\hline Flavonols & 56 & 4.2 & 0.941 & 0.08 & 0.08 & 7.8 & 0.12 \\
\hline Total & 54 & 7.9 & 0.984 & 0.59 & 0.59 & 11.7 & 1.26 \\
\hline
\end{tabular}

${ }^{a} \mathrm{~N}$ : samples used in the internal validation procedure.

b RPD: ratio performance deviation of internal validation (SD/SEP).

c RSQ: coefficient of determination; SEP: standard error of prediction; SEP (C): corrected standard error of prediction. 
Table 5

Internal and external validations of quantitative NIRS models in grape skins ( $\mathrm{mg} \mathrm{g}^{-1}$ of grape skins).

\begin{tabular}{|c|c|c|c|c|c|c|c|}
\hline \multirow[t]{2}{*}{ Phenolic compounds } & \multicolumn{5}{|c|}{ Internal validation ( $\mathrm{N}^{\mathrm{a}}$ samples) } & \multicolumn{2}{|c|}{ External validation (28 samples) } \\
\hline & $\mathrm{N}^{\mathrm{a}}$ & $\mathrm{RPD}^{\mathrm{b}}$ & $\mathrm{RSQ}^{\mathrm{c}}$ & $\operatorname{SEP}^{\mathrm{C}}\left(\mathrm{mg} \mathrm{g}^{-1}\right)$ & $\operatorname{SEP}(C)^{\mathrm{c}}\left(\mathrm{mg} \mathrm{g}^{-1}\right)$ & Differences (\%) & $\mathrm{SEP}^{\mathrm{C}}\left(\mathrm{mg} \mathrm{g}^{-1}\right)$ \\
\hline Anthocyanins & 54 & 4.4 & 0.974 & 0.36 & 0.36 & 17.5 & 0.81 \\
\hline Phenolic acids & 55 & 6.3 & 0.947 & 0.04 & 0.04 & 29.5 & 0.11 \\
\hline Flavanols & 54 & 13.6 & 0.995 & 0.16 & 0.16 & 31.9 & 0.68 \\
\hline Flavonols & 53 & 12.7 & 0.993 & 0.02 & 0.03 & 10.7 & 0.15 \\
\hline Total & 56 & 7.5 & 0.982 & 0.62 & 0.62 & 14.7 & 1.30 \\
\hline
\end{tabular}

a $\mathrm{N}$ : samples used in the internal validation procedure.

b RPD: ratio performance deviation of internal validation (SD/SEP).

c RSQ: coefficient of determination; SEP: standard error of prediction; SEP (C): corrected standard error of prediction.

the presentation form. This confirms a previous studies that showed differences in the same zone using intact grapes, homogenates of grapes and a single grape (Cozzolino et al., 2006).

In order to evaluate NIRS technology models, an internal validation was carried out using samples that belonged to the calibration group after eliminating outliers (in this case only Toutliers). The SD/SEP ratio or ratio performance deviation (RPD) indicates that the performances of calibrations were adequate. Tables 4 and 5 show other descriptors of the internal validation. Fig. 2 and Fig. 3 show the NIRS predicted values versus HPLC values in intact grapes and grape skins respectively.

An external validation (Tables 4 and 5) was performed to check the robustness of the method using the 28 samples that did not belong to the calibration group. Calibration models obtained were applied and the predicted values were compared with the reference data.

The differences between the HPLC reference method and the NIRS technique in external validation are generally smaller in intact grapes than in grape skins except in the case of anthocyanins. For both (grape skins and grapes) minor differences between methods were found in the determination of flavonols. Moreover, the content of total polyphenols show similar and good results in both cases.

Although previous studies have been carried out in intact grape berries in order to determine total anthocyanins (Cozzolino et al., 2006; Cozzolino, Esler et al., 2004), the concentration of extractable anthocyanins at $\mathrm{pH}$ equal to 1.0 and 3.2, the concentration of total polyphenols, the concentration of sugars and the density (Kemps et al., 2010) using near infrared spectroscopy none of them has performed the determination of the main families of phenolic compounds (i.e. flavanols, anthocyanins, flavonols and phenolic acids). In the case of total polyphenols, Kemps et al. did not achieve satisfactory results because they considered the total ITP index instead of the total polyphenols from the skins (Kemps et al., 2010). Regarding anthocyanins other studies have been performed taking into account different varieties of grapes and production areas. The
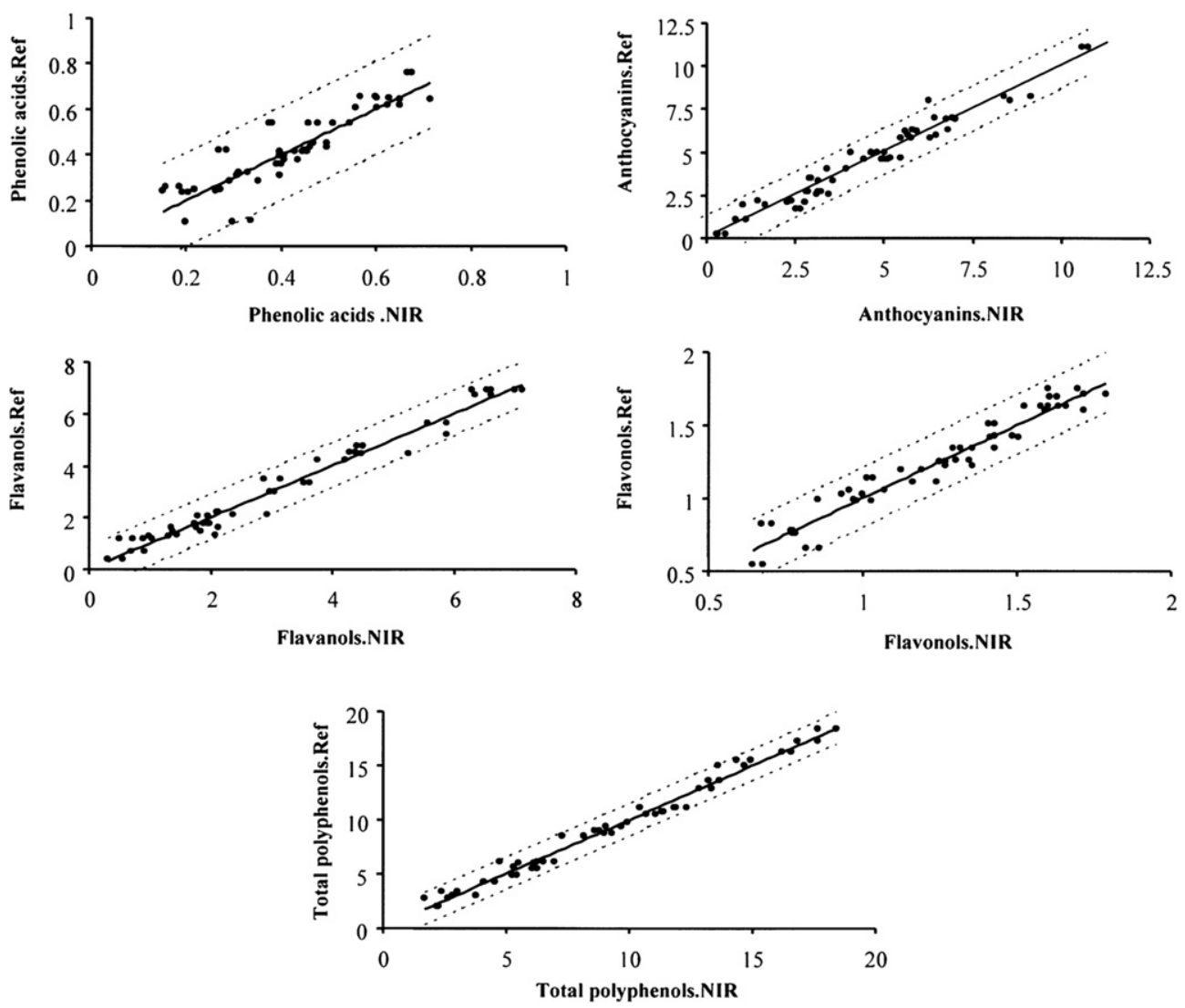

Fig. 2. Comparison of HPLC reference value with the values predicted by the NIRS models in intact grapes ( $\mathrm{mg} \mathrm{g}^{-1}$ of grape skins). 

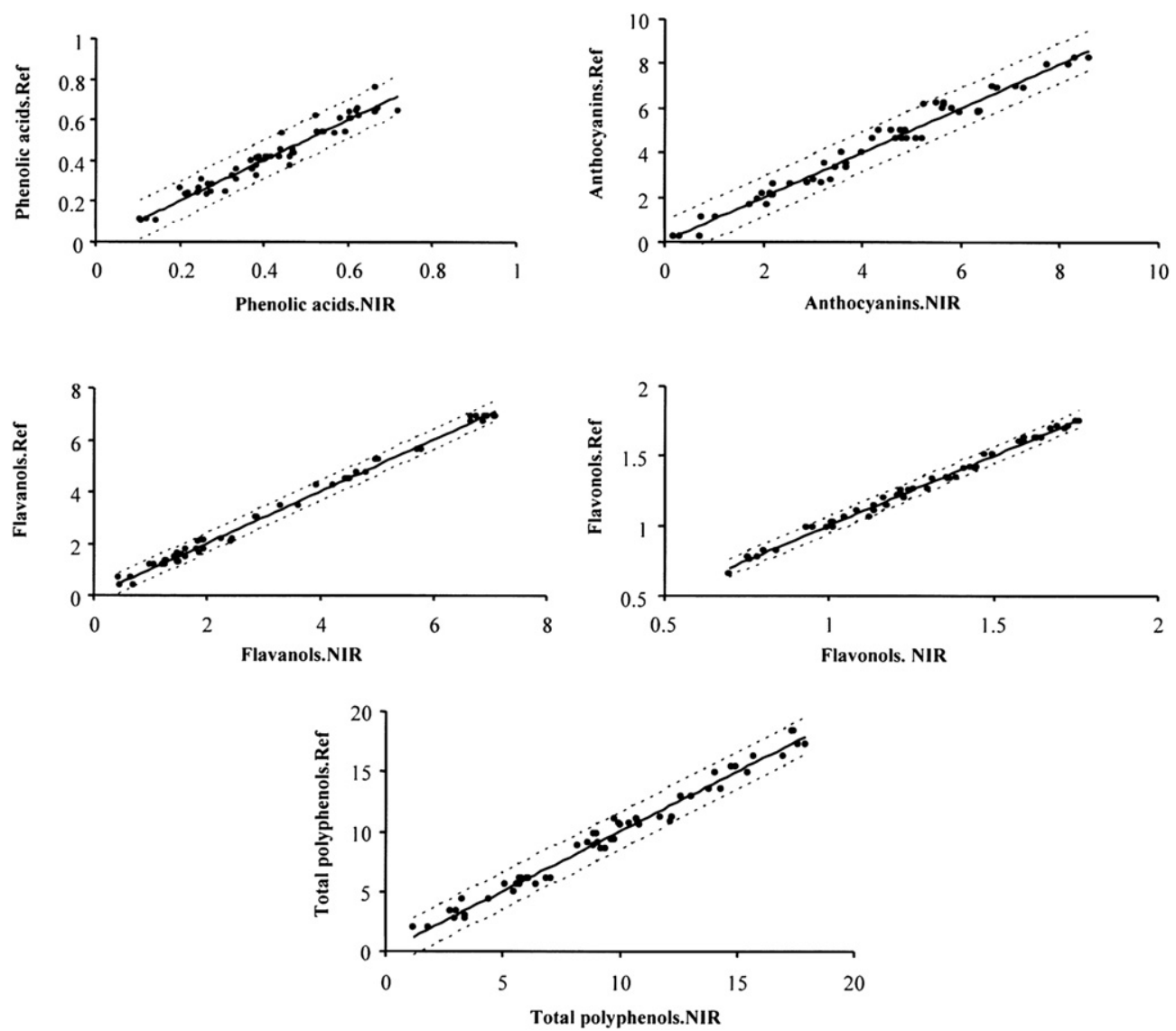

Fig. 3. Comparison of HPLC reference value with the values predicted by the NIRS models in grape skins ( $\mathrm{mg} \mathrm{g}^{-1}$ of grape skins).

SEP values reported for total anthocyanins vary from 0.05 to $0.18 \mathrm{mg} \mathrm{g}^{-1}$ of berry (Cozzolino et al., 2006; Cozzolino, Esler et al., 2004). The obtained results (e.g. range and SEP) in our case were comparable to the results obtained in these studies.

\section{Conclusions}

The results of this work show that the models developed using NIRS technology together with chemometric tools allow the determination, directly in grapes and in grape skins, of the concentrations of total polyphenols and the families of main polyphenols throughout maturation. The best results were generally obtained using a fibre-optic probe and directly recording the spectra of intact grapes, which can be attributable to the practical absence of manipulation of the samples that is needed. The technique reported here is a good option for a rapid quantification of total polyphenols and the families of main polyphenols, the results being comparable with the high-cost and time-consuming analysis methods. The development and application of this technique could become an accurate and efficient tool to aid decision making at harvest time. Nonetheless, a comprehensive study should be made in order to evaluate factors, such as different production areas and grape varieties, in the development of these models.

\section{Acknowledgements}

Thanks are due to the Spanish MICINN (Project ref. AGL200805569-C02-01), Junta de Castilla y León (Grupo de Investigación de Excelencia (GIP/USAL), GR133) and to the Consolider-Ingenio 2010 Programme (FUN-C-FOOD, CSD2007-00063) for financial support.
R. Ferrer-Gallego thanks the Spanish MICINN for the F.P.I. predoctoral scholarship. The authors also thank Bodegas RODA S.A. (Haro, La Rioja, Spain) for supplying the grape samples and Dr. I. GonzálezMartín, who kindly allowed us to use the NIRS instrument.

\section{References}

Boulton, R. (2001). The copigmentation of Anthocyanins and its role in the color of red wine: a critical review. American Journal of Enology and Viticulture, 52, 67-87.

Brereton, R. G. (2003). Chemometrics: Data analysis for the laboratory and chemical plant. Chichester, West Sussex, England: J. Wiley.

Chen, Q., Zhao, J., Liu, M., Cai, J., \& Liu, J. (2008). Determination of total polyphenols content in green tea using FT-NIR spectroscopy and different PLS algorithms. Journal of Pharmaceutical and Biomedical Analysis, 46, 568-573.

Cheynier, V., \& Rigaud, J. (1986). HPLC separation and characterization of flavonols in the skins of Vitis vinifera var. Cinsault. American Journal of Enology and Viticulture, 37, 248-252.

Cozzolino, D., Cynkar, W. U., Dambergs, R. G., Mercurio, M. D., \& Smith, P. A. (2008). Measurement of condensed tannins and dry matter in red grape homogenates using near infrared spectroscopy and partial least squares. Journal of Agricultural and Food Chemistry, 56, 7631-7636.

Cozzolino, D., Dambergs, R. G., Janik, L., Cynkar, W. U., \& Gishen, M. (2006). Review: analysis of grapes and wine by near infrared spectroscopy. Journal of Near Infrared Spectroscopy, 14, 279-289.

Cozzolino, D., Esler, M. B., Dambergs, R. G., Cynkar, W. U., Boehm, D. R., Francis, I. L., et al. (2004). Prediction of colour and pH in grapes using a diode array spectrophotometer (400-1100 nm). Journal of Near Infrared Spectroscopy, 12, 105-111.

Cozzolino, D., Kwiatkowski, M. J., Parker, M., Cynkar, W. U., Dambergs, R. G., Gishen, M., et al. (2004). Prediction of phenolic compounds in red wine fermentations by visible and near infrared spectroscopy. Analytica Chimica Acta, 513, 73-80.

Dhanoa, M. S., Lister, S. J., \& Barnes, R. J. (1995). On the scales associated with nearinfrared reflectance difference spectra. Applied Spectroscopy, 49, 765-772.

Ferrer-Gallego, R., García-Marino, M., Hernández-Hierro, J. M., Rivas-Gonzalo, J. C., \& Escribano-Bailón, M. T. (2010). Statistical correlation between flavanolic 
composition, colour and sensorial parameters in grape seed during ripening. Analytica Chimica Acta, 660, 22-28.

Fragoso, S., Mestres, M., Busto, O., \& Guasch, J. (2010). Comparison of three extraction methods used to evaluate phenolic ripening in red grapes. Journal of Agricultural and Food Chemistry, 58, 4071-4076.

Gómez-Míguez, M., González-Manzano, S., Escribano-Bailón, M. T., Heredia, F. J., \& Santos-Buelga, C. (2006). Influence of different phenolic copigments on the color of malvidin 3-Glucoside. Journal of Agricultural and Food Chemistry, 54, 5422-5429.

García-Marino, M., Hernández-Hierro, J. M., Rivas-Gonzalo, J. C., \& EscribanoBailón, M. T. (2010). Colour and pigment composition of red wines obtained from co-maceration of Tempranillo and Graciano varieties. Analytica Chimica Acta, 660, 134-142.

Geladi, P., MacDougall, D., \& Martens, H. (1985). Linearization and scatter-correction for near-infrared reflectance spectra of meat. Applied Spectroscopy, 39, 491-500.

Goldberg, D. M., Karumanchiri, A., Tsang, E., \& Soleas, G. J. (1998). Catechin and epicatechin concentrations of red wines: regional and cultivar-related differences. American Journal of Enology and Viticulture, 49, 23-34.

Goldberg, D. M., Tsang, E., Karumanchiri, A., \& Soleas, G. J. (1998). Quercetin and p-coumaric acid concentrations in commercial wines. American Journal of Enology and Viticulture, 49, 142-151.

Gonzalez-Manzano, S., Santos-Buelga, C., Perez-Alonso, J. J., Rivas-Gonzalo, J. C., \& Escribano-Bailon, M. T. (2006). Characterization of the mean degree of polymerization of proanthocyanidins in red wines using liquid chromatography and mas spectrometry (LC-MS). Journal of Agricultural and Food Chemistry, 54, 4326-4332.

Hong, V., \& Wrolstad, R. E. (1990). Use of HPLC separation/photodiode array detection for characterization of anthocyanins. Journal of Agricultural and Food Chemistry, 38, 708-715

Janik, L. J., Cozzolino, D., Dambergs, R., Cynkar, W., \& Gishen, M. (2007). The prediction of total anthocyanin concentration in red-grape homogenates using visible-near-infrared spectroscopy and artificial neural networks. Analytica Chimica Acta, 594, 107-118.

Jensen, J. S., Egebo, M., \& Meyer, A. S. (2008). Identification of spectral regions for the quantification of red wine tannins with Fourier transform mid-infrared spectroscopy. Journal of Agricultural and Food Chemistry, 56, 3493-3499.

Kallithraka, S., Bakker, J., \& Clifford, M. N. (1998). Evidence that salivary proteins are involved in astringency. Journal of Sensory Studies, 13, 29-43.

Kemps, B., Leon, L., Best, S., De Baerdemaeker, J., \& De Ketelaere, B. (2010). Assessment of the quality parameters in grapes using VIS/NIR spectroscopy. Biosystems Engineering, 105, 507-513.

Kontoudakis, N., Esteruelas, M., Fort, F., Canals, J. M., \& Zamora, F. (2009) Comparison of methods for estimating phenolic maturity in grapes: correlation between predicted and obtained parameters. Analytica Chimica Acta, 660, 127-133.

López-Sánchez, M., Ayora-Cañada, M. J., \& Molina-Díaz, A. (2009). Olive fruit growth and ripening as seen by vibrational spectroscopy. Journal of Agricultural and Food Chemistry, 58, 82-87.

McGoverin, C. M., Weeranantanaphan, J., Downey, G., \& Manley, M. (2010). Review: the application of near infrared spectroscopy to the measurement of bioactive compounds in food commodities. Journal of Near Infrared Spectroscopy, 18, 87-111.

Monagas, M., Suarez, R., Gomez-Cordoves, C., \& Bartolome, B. (2005). Simultaneous determination of nonanthocyanin phenolic compounds in red wines by HPLCDAD/ESI-MS. American Journal of Enology and Viticulture, 56, 139-147.

Moreno-Arribas, M. V., \& Polo, C. (2008). Wine chemistry and biochemistry. New York, NY: Springer New York.

OIV. (1990). Recuil de methods internationals d'Analyse des vins. Characteristiques chromatiques. Paris: OIV.

Osborne, B. G., Fearn, T., \& Hindle, P. T. (1993). Practical NIR spectroscopy with applications in food and beverage analysis. Harlow, Essex, England, New York: Longman Scientific \& Technical; Wiley.

Preys, S., Mazerolles, G., Courcoux, P., Samson, A., Fischer, U., Hanafi, M., et al. (2006). Relationship between polyphenolic composition and some sensory properties in red wines using multiway analyses. Analytica Chimica Acta, 563, 126-136.

Shenk, J. S., \& Westerhaus, M. O. (1995). Routine operation, calibration, development and network system management manual, NIR systems. MD, USA: Silver Spring.

Siesler, H. W., Ozaky, Y., Kawata, S., \& Heise, H. M. (2002). Near infrared spectroscopy: Principles, instruments, applications. Weinheim, Germany: Wiley-VCH.

Skogerson, K., Downey, M., Mazza, M., \& Boulton, R. (2007). Rapid determination of phenolic components in red wines from UV-visible spectra and the method of partial least squares. American Journal of Enology and Viticulture, 58, 318-325.

Versari, A., Parpinello, G. P., Mattioli, A. U., \& Galassi, S. (2008). Determination of grape quality at harvest using Fourier-transform mid-infrared spectroscopy and multivariate analysis. American Journal of Enology and Viticulture, 59, $317-322$.

Whitacre, E., Oliver, J., van den Broek, R., van Engelen, P., Kremers, B., van der Horst, B., et al. (2003). Predictive analysis of cocoa procyanidins using nearinfrared spectroscopy techniques. Journal of Food Science, 68, 2618-2622.

Wulf, L. W., \& Nagel, C. W. (1978). High-pressure liquid chromatographic separation of anthocyanins of Vitis vinifera. American Journal of Enology and Viticulture, 29, $42-49$. 